\title{
Dépistage actif chez les groupes courant un risque accru de contracter le SRAS-CoV-2 au Canada : coûts et ressources humaines nécessaires
}

\author{
Jonathon R. Campbell PhD, Aashna Uppal MSP, Olivia Oxlade PhD, Federica Fregonese MD PhD, \\ Mayara Lisboa Bastos MD MSc, Zhiyi Lan MSc, Stephanie Law PhD, Chi Eun Oh MD MSc, W. Alton Russell MSc, \\ Giorgia Sulis MD, Nicholas Winters MSc, Mercedes Yanes-Lane MD MSP, Marc Brisson PhD, Sonia Laszlo PhD, \\ Timothy G. Evans MD PhD, Dick Menzies MD MSc
}

Citation : CMAJ 2020 October 5;192:E1146-55. doi : 10.1503/cmaj.201128-f; diffusion hâtive le 9 septembre 2020

Voir la version anglaise de l'article ici : www.cmaj.ca/lookup/doi/10.1503/cmaj.201128; voir l'éditorial connexe (en anglais) ici : www.cmaj.ca/lookup/doi/10.1503/cmaj.202120

\section{RÉSUMÉ}

CONTEXTE : Le dépistage du coronavirus du syndrome respiratoire aigu sévère 2 (SRAS-CoV-2) est en grande partie passif, ce qui nuit au contrôle de l'épidémie. Nous avons élaboré des stratégies de dépistage actif du SRAS-CoV-2 au moyen d'une amplification en chaîne par polymérase couplée à une transcription inverse (RT-PCR) chez les groupes courant un risque accru de contracter le virus dans les provinces canadiennes.

MÉTHODES : Nous avons identifié 5 groupes qui devraient être prioritaires pour le dépistage actif au moyen d'une RT$\mathrm{PCR}$, soit les gens ayant été en contact avec une personne infectée par le SRAS-CoV-2 et ceux qui appartiennent à 4 populations à risque : employés d'hôpitaux, travailleurs en soins de santé communautaires ainsi qu'employés et résidents d'établissements de soins de longue durée, employés d'entreprises essentielles, et élèves et personnel scolaire. Nous avons estimé les coûts, les ressources humaines et la capacité de laboratoire nécessaires au dépistage des membres de ces groupes ou au dépistage sur des échantillons aléatoires aux fins de surveillance.

RÉSULTATS : Du 8 au 17 juillet 2020, 41751 dépistages par RT-PCR étaient réalisés chaque jour en moyenne dans les provinces canadiennes; nous avons estimé que ces tests mobilisaient 5122 employés et coûtaient 2,4 millions de dollars par jour (67,8 millions de dollars par mois). La recherche et le dépistage systématiques des contacts requerraient 1,2 fois plus de personnel et porteraient les coûts mensuels à 78,9 millions de dollars. S'il était réalisé en 1 mois, le dépistage de tous les employés des hôpitaux nécessiterait 1823 travailleurs supplémentaires et coûterait 29,0 millions de dollars. Pour la même période de temps, le dépistage de tous les travailleurs en soins de santé communautaires et de tous les employés et résidents des établissements de soins de longue durée nécessiterait 11074 employés supplémentaires et coûterait 124,8 millions de dollars, et celui de tous les travailleurs essentiels nécessiterait 25965 employés supplémentaires et coûterait 321,7 millions de dollars. Enfin, le dépistage sur 6 semaines de la population scolaire nécessiterait 46368 employés supplémentaires et coûterait 816,0 millions de dollars. Les interventions visant à pallier les inefficacités, comme le dépistage à partir d'échantillons de salive et le regroupement des échantillons, pourraient réduire les coûts de $40 \%$ et les besoins en personnel, de $20 \%$. Le dépistage de surveillance sur des échantillons de la population autre que les contacts coûterait $5 \%$ des coûts associés à l'adoption d'une approche universelle de dépistage auprès des populations à risque.

INTERPRÉTATION : Le dépistage actif des groupes courant un risque accru de contracter le SRAS-CoV-2 semble faisable et favoriserait la réouverture sûre et à grande échelle de l'économie et des écoles. Cette stratégie semble également abordable lorsque comparée aux 169,2 milliards de dollars versés par le gouvernement fédéral dans la lutte contre la pandémie en date de juin 2020. our freiner la propagation du coronavirus du syndrome respiratoire aigu sévère 2 (SRAS-CoV-2) - le pathogène à l'origine de la maladie à coronavirus 2019 (COVID-19) - de nombreux pays ont adopté des mesures d'isolement social ${ }^{1,2}$. Ces mesures, en grande partie efficaces, ont toutefois eu des répercussions écono- miques considérables. En juin 2020, on estimait le coût de la réponse fédérale à la pandémie à 169,2 milliards de dollars ${ }^{3}$. Le taux de chômage était alors de $12 \%{ }^{4}$, et on s'attend à ce que le produit intérieur brut réel chute à $8,4 \%$ en $2020^{5}$. Étant donné ces répercussions, des demandes visant la réouverture rapide de l'économie ont été faites ${ }^{6,7}$. 
L'amplification en chaîne par polymérase couplée à une transcription inverse (RT-PCR) est principalement utilisée pour dépister les infections aiguës par le SRAS-CoV- ${ }^{8}$. Au départ, la capacité limitée du système de santé a fait en sorte que le dépistage par la RT-PCR était réservé aux personnes présentant des symptômes de COVID-19-11. Par la suite, le développement de la capacité et la maîtrise de la première vague ont rendu possible le dépistage chez les personnes asymptomatiques ou n'ayant que peu de symptômes ${ }^{12}$. Selon des études de modélisation, ces personnes seraient à l'origine de plus de $50 \%$ de la transmission communautaire ${ }^{13-16}$. Ces résultats sont d'ailleurs corroborés par des études ayant déterminé que l'excrétion virale commence avant l'apparition des symptômes ${ }^{17,18}$, ainsi que par des séries de cas faisant état d'une transmission importante par les personnes asymptomatiques ${ }^{19-22}$. C'est pourquoi le dépistage de l'infection chez les personnes qui présentent peu ou pas de symptômes semble faire intégrante d'une stratégie exhaustive visant à rouvrir l'économie sans provoquer de recrudescence des $\operatorname{cas}^{16}$.

Or, l'approche de dépistage adoptée à ce jour est surtout passive $^{23,24}$, laissant aux citoyens la responsabilité de subir un test. Les personnes qui courent un risque accru de contracter le SRASCoV-2 sont donc peu susceptibles d'en demander un, à moins de présenter des symptômes. Une stratégie active, reposant sur le dépistage de tous les membres des groupes à risque, permettrait de repérer les personnes infectées n'ayant que peu ou pas de symptômes. Ainsi, on saurait qui peut contribuer à la transmission communautaire, et on disposerait de données épidémiologiques importantes sur les répercussions du SRAS-CoV-2 pour ces populations. En milieu de travail et en milieu scolaire, le dépistage permettrait aux établissements de rester ouverts en toute sûreté.

Nous avons cherché à estimer les coûts, les ressources humaines et la capacité de laboratoire nécessaires aux stratégies de dépistage actif de l'infection par le SRAS-CoV-2 au moyen de la RT-PCR chez les groupes courant un risque accru d'infection au Canada.

\section{Méthodes}

\section{Groupes pour le dépistage actif}

Nous avons déterminé 5 groupes qui devraient être prioritaires pour le dépistage actif en fonction de la prévalence attendue de l'infection par le SRAS-CoV-2 (annexe 1, figure e1, accessible en anglais au www.cmaj.ca/lookup/doi/10.1503/cmaj.201128/tab -related-content). Le premier groupe est formé des gens qui ont été en contact, dans leur ménage ou à l'extérieur de celui-ci, avec une personne ayant récemment reçu un diagnostic d'infection par le SRAS-CoV-2 (stratégie 1). Les gens de ce groupe feraient l'objet d'une recherche de contacts et d'un dépistage systématiques, à raison de 2 membres et de 14 non membres du ménage, en moyenne $e^{25,26}$. Les 4 autres groupes comprennent des populations considérées "à risque ", c'est-à-dire les employés des hôpitaux de soins actifs (stratégie 2), les travailleurs en soins de santé communautaires ainsi que les employés et les résidents des établissements de soins de longue durée (stratégie 3), les employés des entreprises essentielles de domaines autres que la santé où les contacts interpersonnels ou avec le public sont nombreux (stratégie 4), de même que les élèves et les employés des écoles primaires et secondaires (stratégie 5). Pour chaque groupe, nous avons estimé les coûts, les besoins en ressources humaines et la capacité de laboratoire associés à la mise en œuvre de stratégies de dépistage actif, en plus du statu quo. Nous avons défini le statu quo comme correspondant à la période du 8 au 17 juillet, qui comprend le dépistage des personnes symptomatiques et, dans une certaine mesure, celui des personnes asymptomatiques (p. ex., certaines personnes exposées ou à risque de l'être).

\section{Paramètres épidémiologiques, de dépistage et populationnels}

Nous avons recueilli des données épidémiologiques et de dépistage en lien avec le SRAS-CoV-2, puis avons estimé la taille des groupes qui devraient subir un test dans les provinces canadiennes (les territoires du Canada ne comptaient aucun cas actif de COVID-19 au 17 juillet 2020 et ont donc été exclus de l'analyse) (annexe 1, tableau e1).

Le 17 juillet 2020, on recensait 488 centres de dépistage du SRAS-CoV-2. On estime que la capacité de laboratoire s'élevait alors à 80750 RT-PCR par jour. Du 8 au 17 juillet 2020, 417508 tests ont été effectués, et 3501 d'entre eux (0,84\%) ont donné des résultats positifs ${ }^{27}$ (annexe 1, tableau e2).

Nous nous sommes servis de données de Statistique Canada pour connaître le nombre d'hôpitaux de soins actifs et d'établissements de soins de longue durée ${ }^{28,29}$, leur nombre d'employés en juin $2020^{4,30}$, et le nombre de résidents en soins de longue durée $e^{31,32}$. Comme aucune estimation du nombre de travailleurs en soins de santé communautaires n'était disponible pour le Canada ${ }^{33}$, nous avons utilisé des données américaines ${ }^{34-36}$ et avons supposé que le nombre de travailleurs canadiens était proportionnel à la population. Nous avons consulté les données du recensement de 2016 pour connaître le nombre d'employés pour chaque code de la Classification nationale des professions ${ }^{37}$, puis avons ajusté ces données selon la taille de la main-d'œuvre en juin $2020^{4}$. Trois auteurs (J.R.C., N.W. et S.L.) ont déterminé de façon indépendante quels emplois sont essentiels, à l'aide de la définition stricte formulée par la province de Québec en mars $2020^{38}$. Nous nous sommes ensuite servis d'un algorithme publié ${ }^{39}$ et validé au moyen d'O ${ }^{\star} N E T^{40}$ pour repérer les emplois essentiels ne pouvant être effectués à domicile, puis avons déterminé si chacun de ces emplois comportait un risque élevé de contacts interpersonnels ou de contacts avec le public (annexe 1, tableau e3). Des données de Statistique Canada ${ }^{41}$ et de rapports provinciaux ont été utilisées pour estimer le nombre d'écoles primaires et secondaires, ainsi que leur nombre d'élèves et d'employés. Pour plus de détails à ce sujet, consulter l'annexe 1, tableau e4.

\section{Stratégies de dépistage : coûts et ressources humaines nécessaires}

Pour guider la mise en œuvre de stratégies de dépistage actif, nous avons créé un cadre conceptuel en 6 étapes et l'avons appliqué aux 5 groupes : 1) prise de rendez-vous, 2) prélèvement, 3) transport du test, 4) analyse en laboratoire par RT-PCR, 
5) transmission des résultats, et 6) intervention en fonction des résultats (p. ex., recherche des contacts). À la suite de discussions avec des autorités de santé publique et des gestionnaires de laboratoire du Québec, nous avons estimé les ressources humaines nécessaires à chaque étape des diverses stratégies. Tous les renseignements relatifs aux stratégies sont fournis dans l'annexe 1 . En gros, nous avons estimé le nombre de professionnels de la santé, d'employés administratifs et de professionnels de laboratoire nécessaires par jour ( 1 jour équivaut à 8 heures; nous avons pris le personnel à temps partiel en considération), pour chaque stratégie. Nous avons supposé que les prélèvements seraient faits dans les centres existants par des infirmières, ou sur place par des équipes de soins mobiles. Ces équipes visiteraient les établissements de soins comptant au moins 5 employés, les entreprises essentielles ayant au moins 20 employés, et toutes les écoles; les contacts et les personnes se trouvant dans un établissement qui ne répond pas à ces critères seraient dirigés vers les centres de prélèvement existants. Nous avons également réalisé une microanalyse des coûts récurrents (en dollars canadiens de 2020) d'un point de vue systémique. Ces coûts comprennent ceux associés aux fournitures (p. ex., équipement de protection individuelle [EPI], écouvillons nasopharyngés, réactifs), au personnel et au transport. Enfin, nous avons obtenu des données sur les coûts auprès de sources représentatives à l'échelle nationale. Nous n'avons pas tenu compte des coûts en capital liés au renforcement des capacités (p. ex., équipement, formation) et au développement des infrastructures existantes.

\section{Analyse du dépistage universel}

Nous avons estimé les coûts ainsi que les ressources humaines et la capacité de laboratoire nécessaires pour chaque stratégie, en supposant que l'entièreté des populations ciblées subisse un dépistage. Nous avons ensuite fait des estimations pour chaque province, puis les avons additionnées. Nous avons aussi considéré que la recherche et le dépistage systématiques des contacts resteraient prioritaires - comme c'est le cas pour d'autres maladies infectieuses ${ }^{42}-$ et seraient maintenus. Nous donnons donc le coût mensuel associé à la recherche et au dépistage systématiques des contacts. En ce qui concerne les populations à risque, il est possible qu'elles aient à subir 1 ou plusieurs dépistages, selon la prévalence de la maladie et le risque d'infection; c'est pourquoi nous fournissons des estimations quant aux coûts, aux ressources humaines et à la capacité de laboratoire nécessaires à un cycle de dépistage sur une période réaliste. Nous avançons aussi des estimations relatives au dépistage des populations à risque pendant le maintien de la recherche et du dépistage systématiques des contacts. Nous avons considéré qu'un cycle de dépistage prendrait 28 jours pour les employés d'hôpitaux, les travailleurs en soins de santé communautaires, les personnes des établissements de soins de longue durée et les travailleurs essentiels, et 42 jours pour la population scolaire.

Pour chaque stratégie, nous avons calculé séparément les coûts en aval du dépistage répété ainsi que de la recherche et du dépistage des contacts. En ce qui concerne la stratégie visant la recherche et le dépistage des contacts, nous avons estimé les coûts liés à un test supplémentaire chez les personnes ayant obtenu un résultat négatif au premier test, et à 2 tests supplémentaires chez celles ayant obtenu un résultat positif. Pour les stratégies relatives aux populations à risque, nous avons estimé les coûts de 2 tests supplémentaires chez les personnes qui ont eu un résultat positif, ainsi que les coûts associés à la recherche et au test de 16 de leurs contacts.

\section{Analyse du dépistage de surveillance et du dépistage répété}

Il est possible, selon le stade de l'épidémie et la prévalence de la maladie dans la population, que le dépistage systématique de toutes les personnes à risque ne soit pas nécessaire et que le dépistage de surveillance - dépistage aléatoire sur des échantillons de la population - soit préférable. Nous avons estimé les coûts, les ressources humaines et la capacité de laboratoire nécessaires au dépistage de surveillance pendant 14 jours dans les populations à risque. Nous nous sommes servis de la prévalence estimée de l'infection par le SRAS-CoV-2 au 17 juillet 2020 pour calculer la taille d'échantillon nécessaire à l'évaluation de la prévalence dans chaque groupe (annexe 1, tableau e5), et avons refait ces calculs en supposant une prévalence 10 fois plus élevée (annexe 1, tableau e6). Nous avons estimé la taille des échantillons à un niveau de confiance de $95 \%$, en tenant compte de la taille limitée des échantillons ${ }^{43}$ et en supposant que la taille de l'échantillon correspondait à $10 \%$ des personnes de chaque école ou établissement. Pour plus de détails, consulter l'annexe 1.

Afin de savoir à quel moment répéter le dépistage chez les populations à risque, nous avons calculé le temps jusqu'à une nouvelle infection par le SRAS-CoV-2 en fonction de la taille du groupe et du risque d'infection quotidien. Les groupes comptaient de 10 à 1000 personnes, et le risque d'infection quotidien allait de 1 pour 100000 à 1 pour 100 (en supposant une période de contagion de 10 jours ${ }^{44}$; les risques quotidiens se rapprochent des estimations de la prévalence dans la population, qui sont de $0,01 \%$ à $10 \%$, respectivement). À l'aide d'une distribution binomiale de ces paramètres, nous avons réalisé 1000 simulations dans R (version 3.6.3) sur une période de 2 ans. Nous nous sommes servis de ces simulations pour calculer le $10^{\mathrm{e}}$, le $25^{\mathrm{e}}$ et le $50^{\mathrm{e}}$ centile du temps jusqu'à la prochaine nouvelle infection (consulter l'annexe 1 pour connaître le code utilisé).

\section{Analyses de sensibilité}

Nous avons d'abord mené des analyses de sensibilité pour le dépistage universel, en cherchant des manières de réduire les coûts et les inefficacités : prélèvement de salive plutôt que d'échantillons nasopharyngés (sensibilité comparative d'environ $90 \%{ }^{45-50}$, temps de prélèvement réduit de moitié), milieu de transport salin plutôt que propre au virus (aucune perte de sensibilité51), extraction par la chaleur plutôt qu'avec des réactifs (sensibilité comparative d'environ $\left.91 \%{ }^{52-54}\right)$, et regroupement de 4 échantillons pour la RT-PCR (aucune perte de sensibilitée ${ }^{55,56}$ ) (annexe 1, tableau e6). Nous avons aussi réalisé d'autres analyses de sensibilité pour le dépistage universel, et avons réalisé une analyse unidirectionnelle des coûts, des ressources humaines nécessaires et du nombre de contacts estimé pour les stratégies 1 et 4 . Comme ces 2 stratégies reposent sur des 
modèles organisationnels différents en ce qui a trait au prélèvement d'échantillons (les contacts subissent un dépistage en clinique, tandis que les travailleurs le subissent en milieu de travail), les résultats sont présentés dans des graphiques en tornade. Nous avons examiné les changements en matière de coûts et de ressources humaines se produisant selon que l'adoption du dépistage (consentement) était de $90 \%$, de $80 \%$ ou de $60 \%$. Nous avons aussi estimé les coûts et les ressources humaines supplémentaires nécessaires si le prélèvement pour la RT-PCR était accompagné d'un prélèvement de sang total en vue d'un essai immuno-enzymatique. Afin d'évaluer la sensibilité des estimations à la prévalence de l'infection par le SRAS-CoV-2, nous avons multiplié la prévalence estimée par 2, puis par 10, et avons recalculé les coûts et les ressources humaines nécessaires.

\section{Approbation éthique}

L'approbation éthique n'avait pas à être demandée pour cette étude.

\section{Résultats}

\section{Analyse du dépistage universel}

Les coûts, les ressources humaines et la capacité de laboratoire associés à chacune des stratégies sont présentés dans le tableau 1 et le tableau 2 pour l'ensemble du Canada, et dans l'annexe 1 (tableau e8) pour chacune des provinces.

L'approche de dépistage adoptée du 8 au 17 juillet 2020 (statu quo) - qui a permis 41751 tests par jour dans 488 centres de prélèvement - a coûté environ 2,4 millions de dollars par jour (67,8 millions de dollars par mois), et a nécessité 755 infirmières, 213 infirmières auxiliaires, 172 autres professionnels de la santé, 3261 employés administratifs et non cliniciens, et 721 employés de laboratoire (total : 5122 personnes). Les changements relatifs à la capacité de laboratoire et aux besoins en ressources humaines associés à chaque stratégie sont présentés dans la figure 1.

\section{Stratégie 1 : Recherche et dépistage systématiques des contacts}

Comme le montrent les tableaux 1 et 2 , la recherche et le dépistage systématiques des contacts, en plus du statu quo, donneraient lieu à 47353 tests par jour. Toutes les provinces auraient une capacité de laboratoire suffisante (annexe 1, tableau e8). Le personnel administratif nécessaire serait multiplié par 1,2, pour atteindre 3920 personnes, et les coûts mensuels totaux seraient de 78,9 millions de dollars (11,1 millions de dollars par mois de plus que le statu quo). Dans cette stratégie, le nombre de tests répétés chez les personnes infectées et les contacts négatifs serait de 180840 tests par mois, ce qui représente 9,9 millions de dollars de plus.

\section{Stratégies 2 à 5 : Dépistage chez les populations à risque}

Les tableaux 1 et 2 présentent les besoins en ressources humaines, ainsi que la capacité de laboratoire et les coûts associés au dépistage de l'entièreté des populations à risque sur une période donnée. Le dépistage du personnel hospitalier sur 1 mois nécessiterait 439 professionnels de la santé, 890 employés administratifs et 494 professionnels de laboratoire supplémentaires pour tester 27146 personnes par jour, ce qui coûterait 29,0 millions de dollars en tout. Le dépistage, toujours sur 1 mois, des travailleurs en soins de santé communautaires et des personnes des établissements de soins de longue durée nécessiterait quant à lui 4977 professionnels de la santé et 5484 employés administratifs pour tester 35620 personnes par jour, pour un coût total de 124,8 millions de dollars. En ce qui concerne le dépistage sur 1 mois des 2568496 travailleurs essentiels ayant de nombreux contacts interpersonnels ou avec le public, il nécessiterait 11550 professionnels de la santé et 12837 employés administratifs, et coûterait 321,7 millions de dollars. Enfin, le dépistage sur 1 mois et demi des 6012144 élèves et employés des écoles primaires et secondaires nécessiterait 20956 professionnels de la santé, 22950 employés administratifs et 2462 professionnels de laboratoire supplémentaires, ce qui coûterait 816,0 millions de dollars. Les coûts ainsi que les ressources humaines et la capacité de laboratoire nécessaires pour le dépistage des populations à risque, de même que pour la recherche et le dépistage systématiques des contacts, sont présentés dans les tableaux 1 et 2 .

\section{Analyse du dépistage de surveillance et du dépistage répété}

Les estimations relatives aux coûts et aux ressources humaines nécessaires au dépistage de surveillance sur des échantillons de populations à risque sélectionnés aléatoirement se trouvent dans le tableau 3. On a évalué que ce type de dépistage coûterait environ $5 \%$ des coûts du dépistage universel chez les groupes à risque. Les coûts estimés pour chaque cycle de dépistage de surveillance seraient de 2,3 millions de dollars pour les employés des hôpitaux, de 6,6 millions pour les travailleurs en soins de santé communautaires et les employés et résidents des établissements de soins de longue durée, de 14,4 millions de dollars pour les autres travailleurs essentiels, et de 45,6 millions de dollars pour la population scolaire. Toutes les provinces auraient la capacité de laboratoire nécessaire au dépistage de surveillance chez 1 groupe à la fois, simultanément à la recherche et au dépistage systématiques des contacts, mais seules 3 provinces auraient la capacité de le faire chez tous les groupes en même temps (annexe 1, tableau e9).

Dans nos simulations, le facteur déterminant essentiellement la fréquence de répétition du dépistage de surveillance ou du dépistage universel était le risque quotidien d'infection par le SRAS-CoV-2. Si ce risque était de 1 pour 100000 (ce qui correspond à une prévalence d'environ $0,01 \%$ dans la population), les personnes de groupes comptant 100 personnes ou moins (p. ex., effectifs de petite taille, classes d'écoles primaires ou secondaires) avaient plus de $90 \%$ de chances de ne pas être infectées sur une période de plus de 3 mois, ce qui permettait de répéter le dépistage tous les trimestres. Si toutefois le risque était de 1 pour 10000 (prévalence d'environ 0,1\% dans la population), les personnes de groupes comptant 100 personnes ou moins avaient plus de $90 \%$ de chances de ne pas être infectées sur une période d'au moins 4 semaines, ce qui indiquait que le dépistage pouvait être répété chaque mois. Les groupes plus grands ou un risque d'infection plus élevé pourraient justifier des dépistages plus rapprochés (annexe 1, tableau e10). 
Tableau 1 (partie 1 de 2) : Ressources humaines et capacité de laboratoire quotidiennes nécessaires aux stratégies de dépistage actif du SRAS-CoV-2 au Canada

\begin{tabular}{|c|c|c|c|c|c|c|}
\hline \multirow[b]{2}{*}{ Catégories de résultats } & \multirow[b]{2}{*}{$\begin{array}{l}\text { Statu quo : } \\
\text { stratégie } \\
\text { actuelle* }^{\star}\end{array}$} & \multirow[b]{2}{*}{$\begin{array}{l}\text { Stratégie } 1 \text { : } \\
\text { Recherche et } \\
\text { dépistage } \\
\text { systématiques } \\
\text { des contacts } \\
\text { (en plus du } \\
\text { statu quo) }\end{array}$} & \multicolumn{4}{|c|}{ Populations à risque } \\
\hline & & & $\begin{array}{l}\text { Stratégie 2: } \\
\text { Dépistage } \\
\text { chez tous les } \\
\text { employés } \\
\text { d'hôpitaux de } \\
\text { soins actifs }\end{array}$ & $\begin{array}{l}\text { Stratégie } 3 \text { : } \\
\text { Dépistage chez } \\
\text { tous les TSSC } \\
\text { et les employés } \\
\text { et résidents } \\
\text { des } \\
\text { établissements } \\
\text { de soins de } \\
\text { longue durée }\end{array}$ & $\begin{array}{c}\text { Stratégie } 4 \text { : } \\
\text { Dépistage chez } \\
\text { tous les } \\
\text { employés } \\
\text { essentiels ayant } \\
\text { de nombreux } \\
\text { contacts entre } \\
\text { eux ou avec le } \\
\text { public }\end{array}$ & $\begin{array}{c}\text { Stratégie } 5 \text { : } \\
\text { Dépistage } \\
\text { chez tous } \\
\text { les élèves et } \\
\text { les } \\
\text { employés } \\
\text { des écoles }\end{array}$ \\
\hline $\begin{array}{l}\text { Durée des besoins relatifs aux } \\
\text { ressources humaines et à la } \\
\text { capacité (jours) }\end{array}$ & Continue & Continue & 28 & 28 & 28 & 42 \\
\hline $\mathrm{N}^{\text {bre }}$ de personnes testées par jour & 41751 & 47353 & 27146 & 35620 & 91732 & 143146 \\
\hline \multicolumn{7}{|l|}{ Analyse primaire } \\
\hline \multicolumn{7}{|l|}{ Ressources humaines nécessaires $\dagger$} \\
\hline $\begin{array}{l}\mathrm{N}^{\text {bre }} \text { de professionnels de la } \\
\text { santéf }\end{array}$ & 1140 & 1385 & 439 & 4977 & 11550 & 20956 \\
\hline Nore d'employés administratifs§ & 3261 & 3920 & 890 & 5484 & 12837 & 22950 \\
\hline $\begin{array}{l}\mathrm{N}^{\text {bre }} \text { de professionnels de } \\
\text { laboratoire }\end{array}$ & 721 & 818 & 494 & 613 & 1578 & 2462 \\
\hline $\begin{array}{l}\mathrm{N}^{\text {bre }} \text { total de personnes (en } \\
\text { tenant compte de la stratégie } 1 \text { ) }\end{array}$ & - & - & 7946 & 17197 & 32088 & 52491 \\
\hline \multicolumn{7}{|l|}{ Capacité de laboratoire nécessaire } \\
\hline $\begin{array}{l}\mathrm{N}^{\text {bre }} \text { de tests de laboratoire } \\
\text { réalisés chaque jour }\end{array}$ & 41751 & 47353 & 27146 & 35620 & 91732 & 143146 \\
\hline $\begin{array}{l}\mathrm{N}^{\text {bre }} \text { de tests de laboratoire } \\
\text { réalisés chaque jour (en tenant } \\
\text { compte de la stratégie } 1 \text { ) }\end{array}$ & - & - & 74499 & 82972 & 139085 & 190499 \\
\hline \multicolumn{7}{|l|}{ Analyses de sensibilitéđ } \\
\hline \multicolumn{7}{|l|}{ Prélèvement de salive ${ }^{\star \star}$} \\
\hline \multicolumn{7}{|l|}{ Ressources humaines nécessaires $\dagger$} \\
\hline $\begin{array}{l}\text { Changements dans le nombre de } \\
\text { professionnels de la santé } \ddagger\end{array}$ & - & - & -194 & -921 & -2150 & -4090 \\
\hline $\begin{array}{l}\text { Changements dans le nombre } \\
\text { d'employés administratifs§ }\end{array}$ & - & - & -65 & -921 & -2150 & -4090 \\
\hline \multicolumn{7}{|l|}{ Regroupement des échantillons (4:1) } \\
\hline \multicolumn{7}{|l|}{ Ressources humaines nécessaires $\dagger$} \\
\hline $\begin{array}{l}\text { Changements dans le nombre } \\
\text { d'employés administratifs }\end{array}$ & +13 & +19 & +3 & +3 & +3 & +2 \\
\hline $\begin{array}{l}\text { Changements dans le nombre } \\
\text { de professionnels de laboratoire }\end{array}$ & -473 & -525 & -322 & -423 & -1100 & -1718 \\
\hline \multicolumn{7}{|l|}{ Capacité de laboratoire nécessaire } \\
\hline $\begin{array}{l}\text { Changements dans le nombre de } \\
\text { tests de laboratoire réalisés } \\
\text { chaque jour }\end{array}$ & -29880 & -33465 & -19972 & -26216 & -67878 & -105928 \\
\hline $\begin{array}{l}\text { Changements dans le nombre } \\
\text { de tests de laboratoire réalisés } \\
\text { chaque jour (en tenant compte } \\
\text { de la stratégie } 1 \text { ) }\end{array}$ & - & - & -53437 & -59680 & -101342 & -139393 \\
\hline
\end{tabular}




\begin{tabular}{|c|c|c|c|c|c|c|}
\hline \multirow[b]{2}{*}{ Catégories de résultats } & \multirow[b]{2}{*}{$\begin{array}{l}\text { Statu quo: } \\
\text { stratégie } \\
\text { actuelle* }\end{array}$} & \multirow[b]{2}{*}{$\begin{array}{l}\text { Stratégie } 1 \text { : } \\
\text { Recherche et } \\
\text { dépistage } \\
\text { systématiques } \\
\text { des contacts } \\
\text { (en plus du } \\
\text { statu quo) }\end{array}$} & \multicolumn{4}{|c|}{ Populations à risque } \\
\hline & & & $\begin{array}{l}\text { Stratégie 2: } \\
\text { Dépistage } \\
\text { chez tous les } \\
\text { employés } \\
\text { d'hôpitaux de } \\
\text { soins actifs }\end{array}$ & $\begin{array}{l}\text { Stratégie } 3 \text { : } \\
\text { Dépistage chez } \\
\text { tous les TSSC } \\
\text { et les employés } \\
\text { et résidents } \\
\text { des } \\
\text { établissements } \\
\text { de soins de } \\
\text { longue durée }\end{array}$ & $\begin{array}{c}\text { Stratégie } 4 \text { : } \\
\text { Dépistage chez } \\
\text { tous les } \\
\text { employés } \\
\text { essentiels ayant } \\
\text { de nombreux } \\
\text { contacts entre } \\
\text { eux ou avec le } \\
\text { public }\end{array}$ & $\begin{array}{c}\text { Stratégie } 5 \text { : } \\
\text { Dépistage } \\
\text { chez tous } \\
\text { les élèves et } \\
\text { les } \\
\text { employés } \\
\text { des écoles }\end{array}$ \\
\hline \multicolumn{7}{|l|}{ Ensemble des analysestt } \\
\hline \multicolumn{7}{|l|}{ Ressources humaines nécessaires $\dagger$} \\
\hline $\begin{array}{l}\text { Changements dans le nombre de } \\
\text { professionnels de la santé } \neq\end{array}$ & - & - & -194 & -921 & -2150 & -4090 \\
\hline $\begin{array}{l}\text { Changements dans le nombre } \\
\text { d'employés administratifs }\end{array}$ & +13 & +19 & -62 & -918 & -2147 & -4088 \\
\hline $\begin{array}{l}\text { Changements dans le nombre } \\
\text { de professionnels de laboratoire }\end{array}$ & -473 & -525 & -322 & -423 & -1100 & -1718 \\
\hline \multicolumn{7}{|l|}{ Capacité de laboratoire nécessaire } \\
\hline $\begin{array}{l}\text { Changements dans le nombre de } \\
\text { tests de laboratoire réalisés } \\
\text { chaque jour }\end{array}$ & -29880 & -33465 & -19972 & -26216 & -67878 & -105928 \\
\hline $\begin{array}{l}\text { Changements dans le nombre } \\
\text { de tests de laboratoire réalisés } \\
\text { chaque jour (en tenant compte } \\
\text { de la stratégie } 1 \text { ) }\end{array}$ & - & - & -53437 & -59680 & -101342 & -139393 \\
\hline \multicolumn{7}{|c|}{ 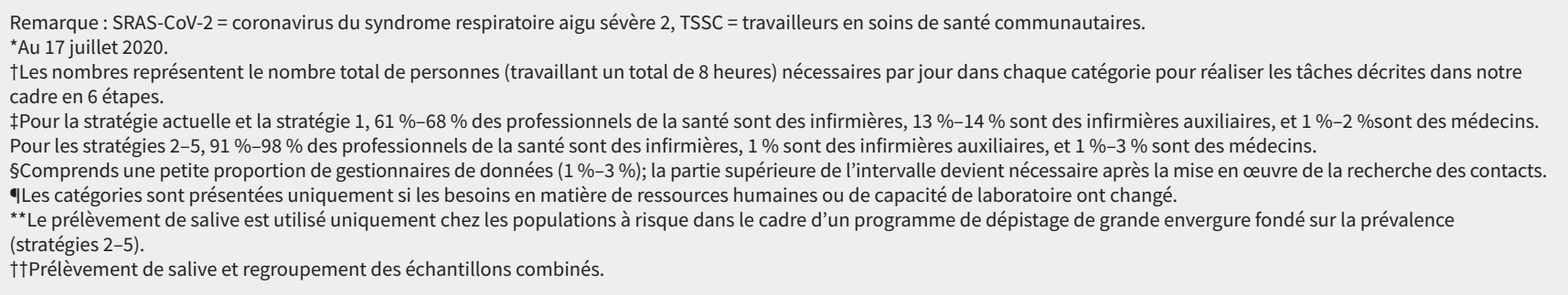 } \\
\hline
\end{tabular}

\section{Analyses de sensibilité}

Il a été prédit que la mise en œuvre d'interventions visant à réduire les coûts et à améliorer l'efficacité aurait des conséquences considérables sur les ressources nécessaires au dépistage universel (tableaux 1 et 2). Le prélèvement d'échantillons de salive réduirait les coûts de $25 \%$ à $30 \%$ et les ressources de soins et administratives requises d'environ $20 \%$. À l'inverse, l'extraction par la chaleur et le milieu de transport salin n'ont pas réduit les besoins en ressources de façon aussi importante. Le regroupement des échantillons, dans une proportion de 4:1, pourrait réduire les réactifs et le temps des techniciens de laboratoire de près de $70 \%$. Pour les stratégies concernant les populations à risque, l'ensemble des interventions a réduit les coûts totaux de $40 \%$ et les besoins en personnel de $20 \%$. Dans une analyse de sensibilité unilatérale, les coûts de la recherche et du dépistage systématiques des contacts étaient les plus sensibles aux coûts des réactifs, et les besoins en personnel étaient les plus sensibles aux activités associées à la recherche des contacts et à la prise de rendez-vous avec ceux-ci. En ce qui concerne le dépistage des travailleurs essentiels à risque, tant les coûts que les besoins en personnel étaient les plus sensibles au temps nécessaire pour obtenir les échantillons (annexe 1, figure e2). L'acceptation réduite du dépistage a donné lieu à une diminution parallèle des ressources humaines nécessaires et des coûts (annexe 1, tableau e11). Le prélèvement d'échantillons sérologiques et leur analyse, combinés à la RT-PCR, coûtaient 31 \$ de plus par personne, en supposant que le coût de chaque test était de $10 \$$ (annexe 1, tableau e11). Les analyses reposant sur la prévalence accrue de l'infection par le SRAS-CoV-2 ont montré une augmentation proportionnelle du nombre de contacts recherchés et soumis à un dépistage dans toutes les stratégies, mais ont également révélé que les stratégies qui visaient les populations à risque n'avaient que des conséquences minimes sur les coûts et les besoins en ressources humaines (annexe 1, tableau e12). 


\begin{tabular}{|c|c|c|c|c|c|c|}
\hline \multirow[b]{2}{*}{ Catégories de résultats } & \multirow[b]{2}{*}{$\begin{array}{l}\text { Statu quo : } \\
\text { stratégie } \\
\text { actuelle }^{\star}\end{array}$} & \multirow[b]{2}{*}{$\begin{array}{l}\text { Stratégie 1: } \\
\text { Recherche et } \\
\text { dépistage } \\
\text { systématiques } \\
\text { des contacts } \\
\text { (en plus du } \\
\text { statu quo) }\end{array}$} & \multicolumn{4}{|c|}{ Populations à risque } \\
\hline & & & $\begin{array}{l}\text { Stratégie 2: } \\
\text { Dépistage } \\
\text { chez tous les } \\
\text { employés } \\
\text { d'hôpitaux de } \\
\text { soins actifs }\end{array}$ & $\begin{array}{l}\text { Stratégie } 3 \text { : } \\
\text { Dépistage chez } \\
\text { tous les TSSC } \\
\text { et les employés } \\
\text { et résidents } \\
\text { des } \\
\text { établissements } \\
\text { de soins de } \\
\text { longue durée }\end{array}$ & $\begin{array}{c}\text { Stratégie 4: } \\
\text { Dépistage chez } \\
\text { tous les } \\
\text { employés } \\
\text { essentiels } \\
\text { ayant de } \\
\text { nombreux } \\
\text { contacts entre } \\
\text { eux ou avec le } \\
\text { public }\end{array}$ & $\begin{array}{l}\text { Stratégie } 5 \text { : } \\
\text { Dépistage chez } \\
\text { tous les élèves } \\
\text { et les employés } \\
\text { des écoles }\end{array}$ \\
\hline $\begin{array}{l}\text { Période de calcul des coûts } \\
\text { (jours) }\end{array}$ & 28 & 28 & 28 & 28 & 28 & 42 \\
\hline $\begin{array}{l}N^{\text {bre }} \text { de personnes testées } \\
\text { chaque jour }\end{array}$ & 41751 & 47353 & 27146 & 35620 & 91732 & 143146 \\
\hline $\begin{array}{l}N^{\text {bre }} \text { de personnes testées } \\
\text { durant la période de calcul }\end{array}$ & 1169028 & 1325872 & 760095 & 997350 & 2568496 & 6012144 \\
\hline \multicolumn{7}{|l|}{ Analyse primaire } \\
\hline \multicolumn{7}{|l|}{ Coûts (\$) } \\
\hline Pour 100 personnes testées & 5800 & 5950 & 3820 & 12520 & 12520 & 13570 \\
\hline Par jour & 2,4 millions & 2,8 millions & 1,0 million & 4,5 millions & 11,5 millions & 19,4 millions \\
\hline $\begin{array}{l}\text { Total pour la période de } \\
\text { calcul }\end{array}$ & 67,8 millions & 78,9 millions & 29,0 millions & 124,8 millions & 321,7 millions & 816,0 millions \\
\hline $\begin{array}{l}\text { Coût total (en tenant } \\
\text { compte de la stratégie 1) }\end{array}$ & - & - & 107,9 millions & 203,7 millions & 400,6 millions & 934,3 millions \\
\hline \multicolumn{7}{|l|}{ Considérations additionnelles } \\
\hline $\begin{array}{l}\mathrm{N}^{\text {bre }} \text { de tests supplémentaires } \\
\text { pour les contacts ou la } \\
\text { répétition du dépistage } \\
\text { durant la période de calcul }^{\dagger}\end{array}$ & 19605 & 180840 & 33790 & 43350 & 43950 & 52600 \\
\hline $\begin{array}{l}\text { Coût total des tests } \\
\text { supplémentaires (\$) }\end{array}$ & 1,2 million & 9,9 millions & 2,1 millions & 2,8 millions & 2,8 millions & 3,3 millions \\
\hline \multicolumn{7}{|l|}{ Analyses de sensibilitéł } \\
\hline \multicolumn{7}{|l|}{ Prélèvement de salive§ } \\
\hline $\begin{array}{l}\text { Économies pendant la } \\
\text { période de calcul }\end{array}$ & - & - & $-5,3$ millions & - 39,6 millions & -91,4 millions & $-257,6$ millions \\
\hline \multicolumn{7}{|l|}{ Milieu de transport salin } \\
\hline $\begin{array}{l}\text { Économies pendant la } \\
\text { période de calcul }\end{array}$ & - 3,9 millions & $-4,4$ millions & $-2,5$ millions & $-3,3$ millions & - 8,5 millions & -20,0 millions \\
\hline $\begin{array}{l}\text { Économies si la stratégie } 1 \\
\text { est exécutée en même } \\
\text { temps }\end{array}$ & - & - & $-6,9$ millions & $-7,7$ millions & - 12,9 millions & - 26,6 millions \\
\hline \multicolumn{7}{|l|}{ Extraction par la chaleur } \\
\hline $\begin{array}{l}\text { Économies pendant la } \\
\text { période de calcul }\end{array}$ & - 12,3 millions & - 14,0 millions & $-8,0$ millions & - 10,5 millions & $-27,1$ millions & $-63,5$ millions \\
\hline $\begin{array}{l}\text { Économies si la stratégie } 1 \\
\text { est exécutée en même } \\
\text { temps }\end{array}$ & - & - & $-22,0$ millions & - 24,5 millions & $-41,1$ millions & - 84,5 millions \\
\hline \multicolumn{7}{|c|}{ Regroupement des échantillons (4:1) } \\
\hline $\begin{array}{l}\text { Économies pendant la } \\
\text { période de calcul }\end{array}$ & - 15,5 millions & - 17,3 millions & - 10,4 millions & - 13,6 millions & $-35,4$ millions & - 83,1 millions \\
\hline $\begin{array}{l}\text { Économies si la stratégie } 1 \\
\text { est exécutée en même } \\
\text { temps }\end{array}$ & - & - & $-27,7$ millions & $-31,0$ millions & $-52,8$ millions & - 109,1 millions \\
\hline
\end{tabular}




\begin{tabular}{|c|c|c|c|c|c|c|}
\hline \multirow[b]{2}{*}{ Catégories de résultats } & \multirow[b]{2}{*}{$\begin{array}{l}\text { Statu quo : } \\
\text { stratégie } \\
\text { actuelle* }^{\star}\end{array}$} & \multirow[b]{2}{*}{$\begin{array}{l}\text { Stratégie } 1 \text { : } \\
\text { Recherche et } \\
\text { dépistage } \\
\text { systématiques } \\
\text { des contacts } \\
\text { (en plus du } \\
\text { statu quo) }\end{array}$} & \multicolumn{4}{|c|}{ Populations à risque } \\
\hline & & & $\begin{array}{l}\text { Stratégie 2: } \\
\text { Dépistage } \\
\text { chez tous les } \\
\text { employés } \\
\text { d'hôpitaux de } \\
\text { soins actifs }\end{array}$ & $\begin{array}{l}\text { Stratégie } 3 \text { : } \\
\text { Dépistage chez } \\
\text { tous les TSSC } \\
\text { et les employés } \\
\text { et résidents } \\
\text { des } \\
\text { établissements } \\
\text { de soins de } \\
\text { longue durée }\end{array}$ & $\begin{array}{l}\text { Stratégie 4: } \\
\text { Dépistage chez } \\
\text { tous les } \\
\text { employés } \\
\text { essentiels } \\
\text { ayant de } \\
\text { nombreux } \\
\text { contacts entre } \\
\text { eux ou avec le } \\
\text { public }\end{array}$ & $\begin{array}{l}\text { Stratégie } 5 \text { : } \\
\text { Dépistage chez } \\
\text { tous les élèves } \\
\text { et les employés } \\
\text { des écoles }\end{array}$ \\
\hline \multicolumn{7}{|l|}{ Ensemble des analyses } \\
\hline $\begin{array}{l}\text { Économies pendant la } \\
\text { période de calcul }\end{array}$ & $-22,9$ millions & $-25,8$ millions & - 17,7 millions & - 56,3 millions & - 135,2 millions & - 356,8 millions \\
\hline $\begin{array}{l}\text { Économies si la stratégie } 1 \\
\text { est exécutée en même } \\
\text { temps }\end{array}$ & - & - & - 43,6 millions & - 82,1 millions & - 161,1 millions & - 395,5 millions \\
\hline \multicolumn{7}{|c|}{$\begin{array}{l}\text { Remarque : SRAS-CoV-2 = coronavirus du syndrome respiratoire aigu sévère } 2, \text { TSSC = travailleurs en soins de santé communautaires. } \\
\text { ×Au } 17 \text { juillet } 2020 \text {. } \\
\text { †En supposant que toutes les personnes qui obtiennent un résultat positif subissent } 2 \text { tests supplémentaires (toutes les stratégies), que tous les contacts qui obtiennent un résultat } \\
\text { négatif subissent un test supplémentaire (stratégie } 1 \text { ), et que tous les contacts retracés subissent un test (stratégies } 2-5 \text { ). } \\
\text { fLes catégories sont présentées uniquement si les coûts ont changé. } \\
\text { SLe prélèvement de salive est utilisé uniquement chez les populations à risque dans le cadre d’un programme de dépistage de grande envergure fondé sur la prévalence (stratégies } 2-5 \text { ). } \\
\text { IPrélèvement de salive, milieu de transport salin, extraction par la chaleur et regroupement des échantillons combinés. Les économies ne s'additionnent pas pour } 2 \text { raisons }: 1 \text { ) le } \\
\text { regroupement des échantillons réduit la quantité de réactifs à utiliser et, par conséquent, diminue les économies associées à l'extraction par la chaleur; 2) le prélèvement de salive ne } \\
\text { nécessite pas de milieu de transport propre au virus, ce qui fait que les économies qu'il occasionne comprennent celles associées au milieu de transport salin. }\end{array}$} \\
\hline
\end{tabular}

\section{Interprétation}

Notre analyse montre que le dépistage actif des populations canadiennes courant un risque accru de contracter le SRASCoV-2 est faisable. La recherche et le dépistage systématiques de 16 contacts par personne ayant récemment reçu un diagnostic d'infection augmentent peu les coûts du dépistage et seraient possibles avec la capacité de laboratoire actuelle. Le dépistage universel chez les populations à risque, quant à lui, coûterait 1,3 milliard de dollars par cycle; même en réalisant plusieurs cycles, les coûts ne représenteraient qu'une petite partie des 169,2 milliards de dollars investis par le gouvernement fédéral (en date de juin 2020) pour lutter contre la pandémie de COVID19. En outre, la mise en œuvre d'interventions visant à réduire les inefficacités dans les procédures de prélèvement et d'analyse en laboratoire pourrait considérablement réduire les coûts. Enfin, le dépistage de surveillance - pour lequel la capacité actuelle est suffisante - est une mesure déterminante et économique permettant de comprendre la portée et la dynamique du SRAS$\mathrm{CoV}-2$ chez les populations à risque.

Nos conclusions contextualisent l'importante réponse nécessaire pour veiller à ce que les populations qui en ont le plus besoin puissent régulièrement subir un dépistage. Les estimations fournies quant aux ressources nécessaires et à la taille des populations sont utiles aux autorités qui cherchent à adopter des stratégies de dépistage actif du SRAS-CoV-2. Les populations canadiennes ciblées par ce type de dépistage sont grandes - environ 4 millions de personnes dans les hôpitaux, en soins communautaires, en soins de longue durée et dans les entreprises essentielles, et 6 millions de personnes dans les écoles - mais des approches ambitieuses semblables ont déjà été préconisées ${ }^{57-59}$. D'autres pays et régions, comme la Corée du Sud ${ }^{60}$, Hong Kong ${ }^{61}$ et l'Allemagne ${ }^{62}$, ont rapidement augmenté leur capacité de dépistage pour faciliter la maîtrise de la première vague épidémique. Des programmes novateurs visant à élargir le dépistage, comme le programme Rapid Acceleration of Diagnostics (RADx) aux États-Unis ${ }^{63}$, sont également en cours. Ces exemples montrent que le déploiement de vastes programmes de dépistage est possible si les gouvernements hiérarchisent leurs efforts, fournissent un financement adéquat, font participer les divers secteurs et tirent parti des ressources humaines.

Le plus grand avantage offert par le dépistage actif est le repérage des personnes qui ne savent pas qu'elles sont infectées par le SRAS-CoV-2 et qui ne présentent que peu ou pas de symptômes. Durant la première vague de COVID-19, la première mesure mise en place pour freiner la propagation de la maladie par ces personnes a été de suspendre de nombreuses activités, ce qui a eu des répercussions sociales et économiques importantes. Nous croyons que le dépistage actif des personnes courant un risque accru de contracter le SRAS-CoV-2 - et l'isolement de celles qui obtiennent un résultat positif - est une façon tout aussi efficace d'éviter la transmission communautaire, à un coût social et économique moindre.

Notre approche comporte aussi d'autres avantages potentiels, comme le renforcement de la capacité de la santé publique et des laboratoires, qui est essentiel pour prévenir une recrudescence de la maladie. La capacité améliorée de la santé publique pourrait également servir à la coordination et à la mise en œuvre ultérieures de la vaccination contre le SRAS-CoV-2. De plus, le 


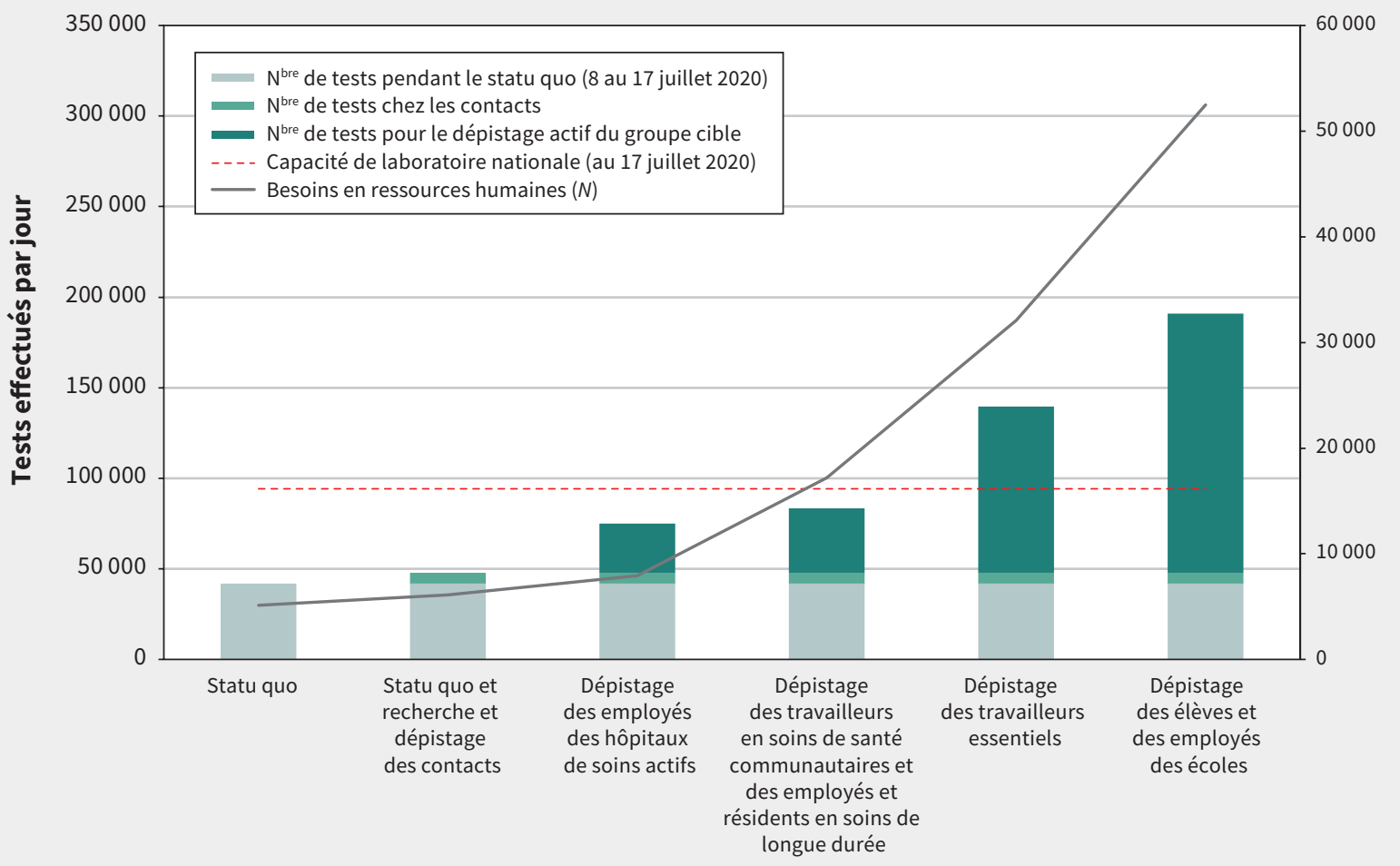

Figure 1 : Changements de la capacité de laboratoire nécessaire selon les stratégies, et changements qui en découlent dans les besoins en ressources humaines (professionnels de la santé, employés administratifs, professionnels de laboratoire). Remarque : nombre total d'employés requis, et capacité de laboratoire nécessaire pour chaque stratégie. La capacité de laboratoire nationale estimée (au 17 juillet 2020) est représentée par une ligne pointillée. Les besoins croissants en capacité de laboratoire ainsi que le nombre total de professionnels pour le dépistage chez les populations à risque sont présentés, en supposant que la recherche et le dépistage systématiques des contacts sont mis en place et maintenus.

dépistage actif fournirait des données épidémiologiques cruciales à la prise de décisions sur les mesures à prendre en matière de dépistage et de contrôle. Si le dépistage de surveillance était adopté immédiatement, les décisions fondées sur des données probantes relatives au dépistage de groupes entiers pourraient être prises au fil de l'augmentation de la capacité. Chez les groupes où la prévalence de l'infection par le SRAS-CoV-2 s'avère faible, le dépistage de surveillance systématique serait primordial pour réagir rapidement à l'augmentation du nombre de cas. Qui plus est, la capacité inutilisée pourrait servir à augmenter la fréquence et la rapidité du dépistage dans les groupes où la prévalence est élevée. Le prélèvement d'échantillons pour des analyses sérologiques ${ }^{64,65}$ et une RT-PCR visant à détecter une infection antérieure ou actuelle pourrait faire augmenter considérablement la valeur du dépistage actif, surtout tant que l'épidémie continue de faire rage.

L'augmentation rapide des ressources humaines et de la capacité de laboratoire est essentielle au succès des stratégies présentées. Elle peut être favorisée par la mobilisation des étudiants en médecine ${ }^{66}$, le recours à d'autres professionnels de la santé $^{67}$ et l'utilisation de laboratoires universitaires et privés ${ }^{68}$. Nos analyses de sensibilité mettent également en évidence d'autres approches pouvant faire accélérer cette augmentation, la principale étant le prélèvement d'échantillons de salive. Ce type de prélèvement serait plus facilement accepté - en particulier chez les enfants, ce qui est important à prendre en considération à la réouverture des écoles - et son analyse a une excellente sensibilitét5-50. En outre, les échantillons de salive éliminent le besoin d'un écouvillonnage nasopharyngé, l'intervention d'un professionnel de la santé pour le prélèvement de l'échantillon et l'utilisation d'EPI coûteux et rare.

\section{Limites de l'étude}

Le prélèvement des échantillons et la recherche des contacts viennent en grande partie des interventions déployées au Québec pendant la première vague de la pandémie, mais ont aussi été validés dans d'autres milieux ${ }^{69-73}$. On note cependant une hétérogénéité entre les systèmes de santé provinciaux, et l'épidémiologie du SRAS-CoV-2 change rapidement. Nous avons mené des analyses de sensibilité en fonction de divers scénarios (p. ex., résurgence de l'épidémie), et de nouvelles approches (p. ex., approbation de tests précis, peu coûteux et réalisés au point d'intervention) peuvent être mises en œuvre avec l'outil que nous avons conçu ${ }^{74}$. Nous n'avons toutefois pas estimé les conséquences épidémiologiques potentielles du dépistage actif, mais nous nous attendons à ce que l'augmentation de la recherche et du dépistage des 


\begin{tabular}{|c|c|c|c|c|c|}
\hline Catégories de résultats & $\begin{array}{l}\text { Employés } \\
\text { d'hôpitaux } \\
\text { de soins } \\
\text { actifs }\end{array}$ & $\begin{array}{l}\text { TSSC et employés et } \\
\text { résidents des } \\
\text { établissements de } \\
\text { soins de longue durée }\end{array}$ & $\begin{array}{l}\text { Employés essentiels } \\
\text { ayant de nombreux } \\
\text { contacts entre eux } \\
\text { ou avec le public }\end{array}$ & $\begin{array}{l}\text { Élèves et } \\
\text { employés } \\
\text { des écoles }\end{array}$ & $\begin{array}{l}\text { Tous les } \\
\text { groupes en } \\
\text { même temps }\end{array}$ \\
\hline \multicolumn{6}{|l|}{ Situation au 17 juillet 2020} \\
\hline $\begin{array}{l}\text { Prévalence estimée du SRAS-CoV-2 dans } \\
\text { la population (\%) }\end{array}$ & 0,25 & 0,25 & 0,1 & 0,05 & - \\
\hline $\mathrm{N}^{\text {bre }}$ total de personnes à tester ${ }^{\star}$ & 60942 & 30462 & 86951 & 302313 & 408668 \\
\hline \multicolumn{6}{|l|}{ Ressources humaines nécessaires } \\
\hline $\mathrm{N}^{\text {bre }}$ de professionnels de la santé & 73 & 588 & 1235 & 3633 & 5529 \\
\hline $\mathrm{N}^{\text {bre }}$ d'employés administratifs & 145 & 619 & 1322 & 3933 & 6019 \\
\hline $\mathrm{N}^{\text {bre }}$ de professionnels de laboratoire & 79 & 37 & 107 & 371 & 595 \\
\hline \multicolumn{6}{|l|}{ Capacité de laboratoire nécessaire } \\
\hline $\begin{array}{l}\mathrm{N}^{\text {bre }} \text { de tests de laboratoire réalisés } \\
\text { chaque jour }\end{array}$ & 4353 & 2176 & 6211 & 21594 & 34333 \\
\hline Coûts du dépistage de tous (\$) & 2,3 millions & 6,6 millions & 14,4 millions & 45,6 millions & 69,1 millions \\
\hline \multicolumn{6}{|c|}{ Situation si la prévalence était 10 fois plus élevée } \\
\hline $\begin{array}{l}\text { Prévalence estimée du SRAS-CoV-2 dans } \\
\text { la population (\%) }\end{array}$ & 2,5 & 2,5 & 1,0 & 0,5 & - \\
\hline $\mathrm{N}^{\text {bre }}$ total de personnes à tester $\dagger$ & 48728 & 19391 & 56403 & 198776 & 323298 \\
\hline \multicolumn{6}{|l|}{ Ressources humaines nécessaires } \\
\hline $\mathrm{N}^{\text {bre }}$ de professionnels de la santé & 58 & 379 & 801 & 2404 & 3642 \\
\hline $\mathrm{N}^{\text {bre }}$ d'employés administratifs & 116 & 399 & 857 & 2601 & 3973 \\
\hline $\mathrm{N}^{\text {bre }}$ de professionnels de laboratoire & 63 & 24 & 69 & 244 & 401 \\
\hline \multicolumn{6}{|l|}{ Capacité de laboratoire nécessaire } \\
\hline $\begin{array}{l}N^{\text {bre }} \text { de tests de laboratoire réalisés } \\
\text { chaque jour }\end{array}$ & 3481 & 1385 & 4029 & 14198 & 23093 \\
\hline Coûts du dépistage de tous (\$) & 1,9 million & 4,3 millions & 9,3 millions & 30,2 millions & 45,7 millions \\
\hline
\end{tabular}

contacts réduise la transmission communautaire, permettant par le fait même aux systèmes de santé de réaliser des économies considérables en aval. D'autres études se sont intéressées aux effets de la recherche et du dépistage des contacts ${ }^{75-77}$. En outre, il est possible que certaines populations visées par nos stratégies subissent déjà un dépistage (p. ex., certains contacts), et nous n'avons pas pris en considération certains groupes qui pourraient en avoir besoin (p. ex., voyageurs, visiteurs en soins de longue durée). Nous nous sommes également servis d'une définition étroite des travailleurs essentiels. De plus, la réouverture des bars et des centres de conditionnement physique et l'augmentation des voyageurs aériens et des clients dans divers secteurs s'accompagneront d'une augmentation du nombre de travailleurs courant un risque accru de contracter le SRAS-CoV-2. Enfin, nous n'avons pas examiné les coûts associés au renforcement de la capacité et aux infrastructures existantes, et nous n'avons pas tenu compte des coûts systémiques autres que ceux associés au dépistage, comme les coûts médicaux à l'interne et à l'externe, la plupart des personnes infectées repérées étant autrement peu susceptibles de chercher à obtenir des soins ou de subir un dépistage.

\section{Conclusion}

Alors que les milieux de travail et les écoles du Canada rouvrent après la première vague de COVID-19, il faut établir des priorités de dépistage et adopter des stratégies pour prévenir les augmentations soudaines dans la transmission communautaire du SRASCoV-2. Les stratégies de dépistage actif peuvent permettre de repérer un grand nombre de personnes infectées par le SRASCoV-2 n'ayant que peu ou pas de symptômes et jouant un rôle important dans ce type de transmission. Nous croyons que l'adoption d'une stratégie de dépistage actif auprès de grands groupes courant un risque accru de contracter le SRAS-CoV-2 est faisable et abordable au Canada. Cette approche de dépistage devrait faire partie intégrante d'une vaste stratégie permettant aux Canadiens de retourner au travail ou à l'école en toute sûreté. 


\section{Références}

1. Hale T, Angrist N, Kira B, et al. Variation in government responses to COVID-19. BSG-WP-2020/032. Version 6.0. Oxford (UK): Blavatnik School of Government, University of Oxford; 2020.. Accessible ici : www.bsg.ox.ac.uk/research/ publications/variation-government-responses-covid-19 (consulté le 24 août 2020).

2. Kaplan J, Frias L, McFall-Johnsen M. Our ongoing list of how countries are reopening, and which ones remain under lockdown. Business Insider 2020 Aug. 18. Accessible ici : www.businessinsider.com/countries-on-lockdown-coronavirus-italy-2020-3 (consulté le 24 août 2020).

3. Scenario analysis update: COVID-19 pandemic and oil price shocks. Ottawa: Office of the Parliamentary Budget Officer; 2020. Accessible ici : www.pbo-dpb.gc.ca/ web/default/files/Documents/Reports/RP-2021-009-S/RP-2021-009-S_en.pdf (consulté le 23 juillet 2020).

4. Labour Force Survey, June 2020. The Daily. Ottawa: Statistics Canada; 2020. Accessible ici : www150.statcan.gc.ca/n1/daily-quotidien/200710/dq200710a -eng.htm (consulté le 14 mai 2020).

5. World economic outlook update: a crisis like no other, an uncertain recovery. Washington (DC): International Monetary Fund; 2020. Accessible ici : www.imf. org/en/Publications/WEO/Issues/2020/06/24/WEOUpdateJune2020 (consulté le 23 juillet 2020)

6. Miller Z, Colvin J, Lemire J. Out to regain footing, Trump shifts virus focus to economy. Daily Herald. 27 avril 2020. Accessible ici : www.dailyherald.com/news /20200427/out-to-regain-footing-trump-shifts-virus-focus-to-economy (consulté le 14 mai 2020).

7. Hinkson K, Shingler B. Legault is gradually reopening Quebec. Are we ready? CBC News. 2020 Apr. 22, updated 2020 Apr. 30. Accessible ici : www.cbc.ca/ news/canada/montreal/quebec-open-schools-economy-covid-19-1.5541594 (consulté le 14 mai 2020).

8. Sethuraman N, Jeremiah SS, Ryo A. Interpreting diagnostic tests for SARSCoV-2. JAMA 2020;323:2249-51.

9. Coronavirus COVID-19. Montréal : Santé Montréal. Accessible ici : santemontreal .qc.ca/population/coronavirus-covid-19/ (consulté le 14 mai 2020).

10. Overview of testing for SARS-CoV-2. Atlanta : Centers for Disease Control and Prevention; 2020. Accessible ici : www.cdc.gov/coronavirus/2019-ncov/hcp/ clinical-criteria.html (consulté le 24 août 2020).

11. Testing in Ottawa now open to anyone with COVID-19 symptoms. CBC News 2020 May 13. Accessible ici : www.cbc.ca/news/canada/ottawa/ottawa -covid19-test-symptoms-1.5567441 (consulté le 14 mai 2020).

12. Neustaeter, B. Can I get tested for COVID-19? What the rules are in each province and territory. CTV News 2020 May 25. Accessible ici : www.ctvnews.ca/health/ coronavirus/can-i-get-tested-for-covid-19-what-the-rules-are-in-each-province -and-territory-1.4953618 (consulté le 23 juillet 2020).

13. Kucharski AJ, Klepac P, Conlan AJK, et al.; CMMID COVID-19 working group. Effectiveness of isolation, testing, contact tracing, and physical distancing on reducing transmission of SARS-CoV-2 in different settings: a mathematical modelling study. Lancet Infect Dis 2020 June 15 [Cyberpublication avant impression]. doi: 10.1016/S1473-3099(20)30457-6.

14. Li R, Pei S, Chen B, et al. Substantial undocumented infection facilitates the rapid dissemination of novel coronavirus (SARS-CoV-2). Science 2020;368:489-93.

15. Koo JR, Cook AR, Park M, et al. Interventions to mitigate early spread of SARSCoV-2 in Singapore: a modelling study. Lancet Infect Dis 2020;20:678-88.

16. Hao X, Cheng S, Wu D, et al. Reconstruction of the full transmission dynamics of COVID-19 in Wuhan. Nature 2020;584:420-4

17. Wiersinga WJ, Rhodes A, Cheng AC, et al. Pathophysiology, transmission, diagnosis, and treatment of coronavirus disease 2019 (COVID-19): a review. JAMA 2020 July 10 [Cyberpublication avant impression]. doi: 10.1001/jama.2020.12839.

18. He X, Lau EHY, Wu P, et al. Temporal dynamics in viral shedding and transmissibility of COVID-19. Nat Med 2020;26:672-5.

19. Bai Y, Yao L, Wei T, et al. Presumed asymptomatic carrier transmission of COVID-19. JAMA 2020;323:1406-7.

20. Li C, Ji F, Wang L, et al. Asymptomatic and human-to-human transmission of SARS-CoV-2 in a 2-family cluster, Xuzhou, China. Emerg Infect Dis 2020;26:1626-8.

21. Ye F, Xu S, Rong Z, et al. Delivery of infection from asymptomatic carriers of COVID-19 in a familial cluster. Int J Infect Dis 2020;94:133-8.

22. Arons MM, Hatfield KM, Reddy SC, et al.; Public Health - Seattle and King County et CDC COVID-19 Investigation Team. Presymptomatic SARS-CoV-2 infections and transmission in a skilled nursing facility. N Engl J Med 2020;382:2081-90.
23. Ministry of Health. COVID-19 provincial testing guidance update. Toronto: Ministry of Health and Long-Term Care; 2020. Accessible ici : www.health.gov.on.ca/ en/pro/programs/publichealth/coronavirus/docs/2019_covid_testing_guidance .pdf (consulté le 23 juillet 2020).

24. Weeks, C. Ontario's contact tracing efforts are falling short, experts say. Globe and Mail [Toronto]. Accessible ici : www.theglobeandmail.com/canada/article -ontarios-contact-tracing-efforts-are-falling-short-experts-say/ (consulté le 23 juillet 2020).

25. Data tables, 2016 Census: structural type of dwelling (10) and household size (8) for occupied private dwellings of Canada, provinces and territories, census divisions and census subdivisions, 2016 Census - 100\% data [tables]. Ottawa: Statistics Canada; modified 2019 June 17. Accessible ici : www12.statcan. gc.ca/census-recensement/2016/dp-pd/dt-td/Rp-eng.cfm?TABID=2\&Lang=E\& APATH $=3 \& D E T A I L=0 \& D I M=0 \& F L=A \& F R E E=0 \& G C=0 \& G I D=1159582 \& G K=0 \& G R P=$ $1 \& P I D=109536 \& P R I D=10 \& P T Y P E=109445 \& S=0 \& S H O W A L L=0 \& S U B=0 \& T e m p o r a l$ $=2016 \& \mathrm{THEME}=116 \& \mathrm{VID}=0 \& \mathrm{VNAMEE}=\& \mathrm{VNAMEF}=\& \mathrm{D} 1=0 \& \mathrm{D} 2=0 \& \mathrm{D} 3=0 \& \mathrm{D} 4=0$ \&D5=0\&D6=0 (consulté le 14 mai 2020).

26. Pringle J. 1,500 close contacts for positive COVID-19 cases in Ottawa: Dr. Etches. CTV News [Ottawa]. 2020 Mar. 25. Accessible ici : ottawa.ctvnews. $\mathrm{ca} / \mathrm{mobile}$ /1-500-close-contacts-for-positive-covid-19-cases-in-ottawa-dr -etches -1.4867734 ? cache=almppngbro?clipld=89950 (consulté le 14 mai 2020).

27. Coronavirus disease 2019 (COVID-19): epidemiology update. Ottawa: Public Health Agency of Canada; modified 2020 Aug. 23. Accessible ici : https:// health-infobase.canada.ca/covid-19/epidemiological-summary-covid-19 -cases.html\#a6 (consulté le 19 juillet 2020).

28. Health care and social assistance: 6221 - General medical and surgical hospitals. In: Summary - Canadian Industry Statistics. Ottawa: Innovation, Science and Economic Development Canada; modified 2020 Mar. 11. Accsesible ici : https:// strategis.ic.gc.ca/app/scr/app/cis/summary-sommaire/6221 (consulté le 14 mai 2020).

29. 623 - Nursing and residential care facilities. In: Businesses - Canadian Industry Statistics. Ottawa: Innovation, Science and Economic Development Canada; modified 2020 Mar. 11. Accessible ici : https://strategis.ic.gc.ca/app/scr/app/cis/ businesses-entreprises/623 (consulté le 14 mai 2020).

30. Data tables, 2016 Census: Industry - North American Industry Classification System (NAICS) 2012 (427A), class of worker (5A), labour force status (3), age (13A) and sex (3) for the labour force aged 15 years and over in private households of Canada, provinces and territories, census metropolitan areas and census agglomerations, 2016 Census - 25\% sample data [tables]. Ottawa: Statistics Canada; modified 2019 June 17. Accessible ici : www12.statcan.gc.ca/census-recensement/ 2016/dp-pd/dt-td/Rp-eng.cfm?LANG=E\&APATH=3\&DETAIL=0\&DIM=0\&FL=A\&FREE $=0 \& G C=0 \& G I D=0 \& G K=0 \& G R P=1 \& P I D=110695 \& P R I D=10 \& P T Y P E=109445 \& S=0 \& S H O$ WALL $=0 \& S U B=0 \&$ Temporal $=2017 \&$ THEME $=124 \& V I D=0 \& V N A M E E=\& V N A M E F=$ (con sulté le 14 mai 2020).

31. Data tables, 2016 Census: type of collective dwelling (16), age (20) and sex (3) for the population in collective dwellings of Canada, provinces and territories, 2016 Census - 100\% data. Ottawa: Statistics Canada; modified 2019 June 17. Accessible ici : www12.statcan.gc.ca/census-recensement/2016/dp-pd/dt-td/Rp-eng.cfm? LANG $=E \& A P A T H=3 \& D E T A I L=0 \& D I M=0 \& F L=A \& F R E E=0 \& G C=0 \& G I D=0 \& G K=0 \& G R P=1$ $\& P I D=109537 \& P R I D=0 \& P T Y P E=109445 \& S=0 \& S H O W A L L=0 \& S U B=0 \& T e m p o r a l=201$ $6 \& T H E M E=116 \& V I D=0 \& V N A M E E=\& V N A M E F=$ (consulté le 14 mai 2020).

32. Table 17-10-0009-01: Population estimates, quarterly [tableau]. Ottawa: Statistics Canada; modified 2020 Aug. 24. Accessible ici : www150.statcan.gc.ca/t1/tbl1/en/ tv.action?pid=1710000901 (consulté le 14 mai 2020).

33. Najafizada SAM, Bourgeault IL, Labonte R, et al. Community health workers in Canada and other high-income countries: a scoping review and research gaps. Can J Public Health 2015;106:e157-64.

34. Rosenthal EL, Brownstein JN, Rush CH, et al. Community health workers: part of the solution. Health Aff (Millwood) 2010;29:1338-42.

35. Occupational employment and wages, May 2019: 21-1094 - Community health workers. Washington (DC): U.S. Bureau of Labor Statistics; modified 2020 July 6. Accessible ici : www.bls.gov/oes/current/oes211094.htm (consulté le 22 juillet 2020).

36. A summary of the National Community Health Advisor study: weaving the future. Tucson (Arizona) : Center for Rural Health, University of Arizona; 1998, reprinted 2000. Accessible ici : crh.arizona.edu/sites/default/files/pdf/publications/ CAHsummaryALL.pdf (consulté le 22 juillet 2020).

37. Data tables, 2016 Census: occupation - National Occupational Classification (NOC) 2016 (693A), industry - North American Industry Classification System (NAICS) 2012 (23A), labour force status (3), age (5) and sex (3) for the Labour Force 
aged 15 years and over in private households of Canada, provinces and territories, census metropolitan areas and census agglomerations, 2016 Census - 25\% sample data. Ottawa: Statistics Canada; modified 2019 June 17. Accessible ici : www12.statcan.gc.ca/census-recensement/2016/dp-pd/dt-td/Rp-eng.cfm?TABID $=2 \&$ Lang $=$ E\&APATH $=3 \& D E T A I L=0 \& D I M=0 \& F L=A \& F R E E=0 \& G C=0 \& G I D=1341679 \& G$ $\mathrm{K}=0 \& \mathrm{GRP}=1 \& \mathrm{PID}=111858 \& \mathrm{PRID}=10 \& \mathrm{PTYPE}=109445 \& \mathrm{~S}=0 \& \mathrm{SHOWALL}=0 \& \mathrm{SUB}=0 \&$ Temporal $=2017 \&$ THEME $=124 \& \mathrm{VID}=0 \& \mathrm{VNAMEE}=\& \mathrm{VNAMEF}=\& D 1=0 \& D 2=0 \& \mathrm{D} 3=0 \& \mathrm{D}$ 4=0\&D5=0\&D6=0 (consulté le 14 mai 2020)

38. Government of Quebec communicates the list of essential services and commercial activities. Montréal: Stikeman Elliott; 2020. Accessible ici : www .stikeman.com/en-ca/kh/corporations-commercial-lawGovernment-of-Quebec -Communicates-the-List-of-Essential-Services-and-Commercial-Activities (consulté le 24 août 2020).

39. Dingel JI, Neiman B. How many jobs can be done at home? Chicago: Becker Friedman Institute for Economics at UChicago; 2020. Accessible ici : bfi. uchicago.edu/wp-content/uploads/BFI_White-Paper_Dingel_Neiman_3.2020.pdf (consulté le 14 mai 2020).

40. O^NET OnLine. [Page d'accueil.] Accessible ici : www.onetonline.org/ (consulté le 14 mai 2020).

41. Table 37-10-0109-01: Number of students in elementary and secondary schools, by school type and program type. Ottawa: Statistics Canada; modified 2020 Aug. 24. Accessible ici : www150.statcan.gc.ca/t1/tbl1/en/tv. action?pid=3710010901 (consulté le 14 mai 2020).

42. WHO consolidated guidelines on tuberculosis: Module 1 - Prevention: tuberculosis preventive treatment. [Ligne directrice.] Geneva: World Health Organization; 2020. Accessible ici : www.who.int/publications-detail-redirect/who-consolidated -guidelines-on-tuberculosis-module-1-prevention-tuberculosis-preventive -treatment (consulté le 31 juillet 2020).

43. Fosgate GT. Practical sample size calculations for surveillance and diagnostic investigations. J Vet Diagn Invest 2009;21:3-14.

44. Coronavirus disease (COVID-19): summary of assumption. Ottawa: Public Health Agency of Canada; 2020. Accessible ici : www.canada.ca/en/public -health/services/diseases/2019-novel-coronavirus-infection/health-professionals /assumptions.html\#a4 (consulté le 15 mai 2020).

45. To KK-W, Tsang OT-Y, Yip CC-Y, et al. Consistent detection of 2019 novel coronavirus in saliva. Clin Infect Dis 2020;71:841-3.

46. Azzi L, Carcano G, Gianfagna F, et al. Saliva is a reliable tool to detect SARSCoV-2. J Infect 2020;81:e45-50.

47. Williams E, Bond K, Zhang B, et al. Saliva as a non-invasive specimen for detection of SARS-CoV-2. J Clin Microbiol 2020;58:e00776-20.

48. Wyllie AL, Fournier J, Casanovas-Massana A, et al. Saliva is more sensitive for SARS-CoV-2 detection in COVID-19 patients than nasopharyngeal swabs. medRxiv 2020 Apr. 22. doi : 10.1101/2020.04.16.20067835.

49. Pasomsub E, Watcharananan SP, Boonyawat K, et al. Saliva sample as a noninvasive specimen for the diagnosis of coronavirus disease 2019: a cross-sectional study. Clin Microbiol Infect 2020 May 15 [Cyberpublication avant impression]. doi: 10.1016/j.cmi.2020.05.001.

50. Jamal AJ, Mozafarilhashjin M, Coomes E, et al.; chercheurs sur la COVID-19 du Toronto Invasive Bacterial Diseases Network. Sensitivity of nasopharyngeal swabs and saliva for the detection of severe acute respiratory syndrome coronavirus 2. Clin Infect Dis 2020 June 15 [Cyberpublication avant impression]. doi: $10.1093 /$ cid/ciaa848.

51. Rodino KG, Espy MJ, Buckwalter SP, et al. Evaluation of saline, phosphate buffered saline and minimum essential medium as potential alternatives to viral transport media for SARS-CoV-2 testing. J Clin Microbiol 2020;58:e00590-20.

52. Fomsgaard AS, Rosenstierne MW. An alternative workflow for molecular detection of SARS-CoV-2 - escape from the NA extraction kit-shortage, Copenhagen, Denmark, March 2020. Euro Surveill 2020;25:2000398.

53. Alcoba-Florez J, González-Montelongo R, Íñigo-Campos A, et al. Fast SARSCoV-2 detection by RT-qPCR in preheated nasopharyngeal swab samples. Int $\mathrm{J}$ Infect Dis 2020;97:66-8.

54. Smyrlaki I, Ekman M, Lentini A, et al. Massive and rapid COVID-19 testing is feasible by extraction-free SARS-CoV-2 RT-qPCR. medRxiv 2020 Aug. 5. doi: 10.1101/2020.04.17.20067348

55. Abdalhamid B, Bilder CR, McCutchen EL, et al. Assessment of specimen pooling to conserve SARS CoV-2 testing resources. Am J Clin Pathol 2020;153:715-8.

56. Lohse S, Pfuhl T, Berkó-Göttel B, et al. Pooling of samples for testing for SARSCoV-2 in asymptomatic people. Lancet Infect Dis 2020 Apr. 28 [Cyberpublication avant impression]. doi: 10.1016/S1473-3099(20)30362-5.
57. Siddarth D, Weyl EG. Why we must test millions a day. COVID-19 Rapid Response Impact Initiative, White Paper 6. Cambridge (Massachusetts) : Edmond J. Safra, Center for Ethics; 2020.

58. Allen D, O'Connor E, Berry S, et al. National COVID-19 Testing Action Plan: pragmatic steps to reopen our workplaces and our communities. New York : Fondation Rockefeller; 2020. Accessible ici : www.rockefellerfoundation.org/ national-covid-19-testing-action-plan/ (consulté le 30 avril 2020).

59. Black JR M, Bailey C, Przewrocka J, et al. COVID-19: the case for health-care worker screening to prevent hospital transmission. Lancet 2020;395:1418-20.

60. Tackling COVID-19: health, quarantine and economic measures - Korean experience. [Communiqué de presse.] Gouvernement de la République de Corée; 2020. Accessible ici : english.moef.go.kr/pc/selectTbPressCenterDtl. do?boardCd=N0001\&seq=4868 (consulté le 14 mai 2020).

61. Gibney E. Whose coronavirus strategy worked best? Scientists hunt most effective policies. Nature 2020;581:15-6.

62. German coronavirus testing capacity increases to 900,000 a week. Stockholm (Suède) : The Local Europe AB; 29 avril 2020. Accessible ici : www.thelocal. de/20200429/german-coronavirus-testing-capacity-increases-to-900000-a-week (consulté le 14 mai 2020).

63. Tromberg BJ, Schwetz TA, Pérez-Stable EJ, et al. Rapid scaling up of COVID-19 diagnostic testing in the United States: the NIH RADx Initiative. N Engl J Med 22 juillet 2020 [Cyberpublication avant impression.] doi : 10.1056/NEJMsr2022263.

64. Lisboa Bastos M, Tavaziva G, Abidi SK, et al. Diagnostic accuracy of serological tests for covid-19: systematic review and meta-analysis. BMJ 2020;370:m2516.

65. COVID-19 Immunity Task Force: helping to guide Canada's epidemic response [main page]. Accessible ici : www.covid19immunitytaskforce.ca/ (consulté le 14 août 2020).

66. Rasmussen S, Sperling P, Poulsen MS, et al. Medical students for health-care staff shortages during the COVID-19 pandemic. Lancet 2020;395:e79-80.

67. Miller DG, Pierson L, Doernberg S. The role of medical students during the COVID-19 pandemic. Ann Intern Med 2020;173:145-6.

68. Kives B. Manitoba boosts COVID-19 testing capacity - but still falls shy of mark set by premier. CBC News 24 juillet 2020. Accessible ici : www.cbc.ca/news/canada/ manitoba/manitoba-cadham-dynacare-covid-testing-1.5661784 (consulté le 14 août 2020).

69. Kwon KT, Ko JH, Shin H, et al. Drive-through screening center for COVID-19: a safe and efficient screening system against massive community outbreak. J Korean Med Sci 2020;35:e123.

70. Lee VJ, Chiew CJ, Khong WX. Interrupting transmission of COVID-19: lessons from containment efforts in Singapore. J Travel Med 2020;27:taaa039.

71. Hsu LY, Chia PY, Vasoo S. A midpoint perspective on the COVID-19 pandemic. Singapore Med J 2020;61:381-3.

72. Seedat J, Paape C. Impfstatus der Kinder und Jugendlichen in Deutschland, STIKO: Influenzaimpfungen in der COVID-19-Pandemie. Epidemiologisches Bulletin. Berlin (Allemagne) : Institut Robert Koch; 2020.

73. ALM - Akkreditierte Labore in der Medizin e.V. [Page d'accueil]. Accessible ici : www.alm-ev.de/startseite.html (consulté le 15 mai 2020).

74. Uppal A, Campbell JR, Oxlade O, et al. An interactive Excel file to estimate costs of expanded testing for COVID-19 by RT-PCR and/or serologic tests. Version 2.0. Genève : CERN, Organisation européenne pour la recherche nucléaire; 2020. Accessible ici : zenodo.org/record/3964991 (consulté le 28 juillet 2020).

75. Hellewell J, Abbott S, Gimma A, et al. Feasibility of controlling COVID-19 outbreaks by isolation of cases and contacts. Lancet Glob Health 2020;8:e488-96.

76. Giordano G, Blanchini F, Bruno R, et al. Modelling the COVID-19 epidemic and implementation of population-wide interventions in Italy. Nat Med 2020;26:855-60.

77. Ali ST, Wang L, Lau EHY, et al. Serial interval of SARS-CoV-2 was shortened over time by nonpharmaceutical interventions. Science 21 juillet 2020 [Cyberpublication avant impression.] doi : 10.1126/science.abc9004. 
Intérêts concurrents : Alton Russell a fourni des services de consultation à Terumo BCT, une entreprise d'appareils médicaux qui ne fabrique pas de tests diagnostiques; ces services n'avaient aucun lien avec la présente étude et ont été offerts hors du cadre de celle-ci. Stephanie Law travaille à temps partiel à Carebook Technologies Inc., une entreprise d'applications technologiques mobiles qui met présentement à l'essai une application permettant de suivre les symptômes de la maladie à coronavirus 2019 (COVID-19). Ce travail n'a aucun lien avec la présente étude et a lieu en dehors de celle-ci. Jonathon Campbell a quant à lui reçu des honoraires de consultant du Groupe de travail sur l'immunité face à la COVID-19 (GTIC) pour des services non liés à la présente étude et rendus à l'extérieur de celle-ci; l'offre des services et la perception des honoraires ont eu lieu après la remise initiale du manuscrit. Olivia Oxlade est directrice scientifique associée (gestion) du GTIC. Sa contribution au manuscrit a eu lieu avant son arrivée à ce poste, alors qu'elle travaillait au Centre international de la tuberculose de McGill. Enfin, Timothy Evans est directeur administratif du GTIC. Aucun autre intérêt concurrent n'a été déclaré.

Cet article a été révisé par des pairs.

Affiliations : Institut de recherche du Centre universitaire de santé McGill (Campbell, Oxlade, Fregonese, Menzies, Oh, Bastos, Sulis); Faculté de médecine (Campbell, Menzies, Winters, Sulis, Uppal, Yanes-Lane, Lan), Université McGill; Centre international de la tuberculose McGill (Campbell, Oxlade, Fregonese, Menzies, Bastos, Sulis, Law); Département d'économie (Laszlo) et École de santé des populations et de santé mondiale (Evans), Université McGill, Montréal (Québec); Département de sciences de la gestion et d'ingénierie (Russell), Université Stanford, Stanford (Californie); Département de pédiatrie (Oh), Collège de médecine de l'Université Kosin, Busan (République de Corée); Département d'épidémiologie (Bastos), Institut de médecine sociale, Université d'État de Rio de Janeiro, Rio de Janeiro (Brésil); Département de santé mondiale et de médecine sociale (Law), Faculté de médecine de Harvard, Boston (Massachusetts); Département de médecine sociale et préventive (Brisson), Université Laval, Québec (Québec).

Collaborateurs : Dick Menzies, Jonathon Campbell, Alton Russell, Timothy Evans et Olivia Oxlade ont contribué à la conception et à la planification de l'étude. Tous les auteurs ont participé à l'acquisition et à l'interprétation des données. Jonathon Campbell, Aashna Uppal et Dick Menzies ont analysé les données. Jonathon Campbell et Dick Menzies ont rédigé la première version du manuscrit. Tous les auteurs ont révisé de façon critique le contenu intellectuel important du manuscrit; ils ont donné leur approbation finale pour la version destinée à être publiée et assument l'entière responsabilité de tous les aspects du travail.

Financement : Cette étude a été directement financée par une subvention de fonctionnement (ECRF-R1-30) de l'Initiative interdisciplinaire en infection et immunité de McGill (MI4), un organisme philanthropique remettant des subventions scientifiques dans le cadre de concours avec évaluation par les pairs. Dick Menzies agissait à titre de chercheur principal et Jonathon Campbell, de cochercheur principal. La subvention a également servi à rémunérer Aashna Uppal et Mercedes Yanes-Lane. Jonathon Campbell (dossiers nos 258907 et 287869) et Stephanie Law (dossier $n^{\circ} 258467$ ) sont titulaires de bourses de recherche postdoctorale du Fonds de Recherche du Québec - Santé. Nicholas Winters (dossier $n^{\circ} 284837$ ) est titulaire d'une bourse de doctorat en recherche du même organisme. W. Alton Russell a reçu une bourse de recherche interdisciplinaire doctorale de Stanford. Mayara Bastos, Federica Fregonese, Nicholas Winters, Jonathon Campbell et Olivia Oxlade ont reçu une subvention des Instituts de recherche en santé du Canada (FRD143350). Giorgia Sulis est titulaire d'une bourse de recherche doctorale Richard H. Tomlinson.

Rôle des bailleurs de fonds : Les bailleurs de fonds n'ont pas participé aux activités suivantes : conception et réalisation de l'étude; collecte, gestion, analyse et interprétation des données; préparation, évaluation et approbation du manuscrit; et soumission de celui-ci aux fins de publication.

Partage des données : Toutes les données ayant servi à la rédaction du manuscrit sont accessibles dans le corps du texte, les documents connexes et notre outil Excel en ligne (https://zenodo.org/record/3964991).

Remerciements : Les auteurs remercient Andrea Benedetti pour ses conseils statistiques sur le dépistage de surveillance, Danielle Sampath pour son soutien administratif et technique, les $D^{\text {rs }}$ Marcel Behr et Cedric Yansouni pour leurs conseils en lien avec les laboratoires, les $D^{\text {rs }}$ Kevin Schwartzman et Raymond Tellier pour leur examen critique d'une version antérieure du présent article, ainsi que la $D^{\text {re }}$ Noémie Savard et tous les représentants d'autorités sanitaires du Québec qui ont fourni des renseignements contextuels importants pour l'élaboration des stratégies analysées et la détermination des ressources nécessaires.

Accepté : 24 août 2020

Correspondance : Dick Menzies, dick.menzies@mcgill.ca 